\title{
Regional differences in an established population of invasive Indo-Pacific lionfish (Pterois volitans and $P$. miles) in south Florida
}

\author{
David R Bryan ${ }^{\text {Corresp., }}{ }^{1,2}{ }^{\text {, Jeremiah Blondeau }}{ }^{3}$, Ashley Siana ${ }^{1}$, Jerald S Ault ${ }^{1}$ \\ 1 Rosenstiel School of Marine and Atmospheric Science, Department of Marine Ecosystems and Society, University of Miami, Miami, Florida, United States \\ 2 Pacific States Marine Fisheries Commission, Alaska Fisheries Science Center, National Marine Fisheries Service, National Oceanic and Atmospheric \\ Administration, Seattle, Washington, United States \\ ${ }^{3}$ Southeast Fisheries Science Center,National Marine Fisheries Service, National Oceanic and Atmospheric Administration, Miami, Florida, United States \\ Corresponding Author: David R Bryan \\ Email address: david.bryan@noaa.gov
}

About nine years ago (circa 2009), Indo-Pacific lionfishes (Pterois volitans and P. miles) invaded the south Florida coral reef ecosystem. During the intervening period of time, there has been substantial research on their biology, life history, demography, and habitat preferences; however, little is known concerning their regional population status and trends in the region. Here, we use a large-scale fisheries independent reef fish visual survey to investigate lionfish population status among three south Florida regions: Dry Tortugas, Florida Keys, and southeast Florida. Density estimates (ind ha-1) have been relatively stable since 2012, and are lower than other areas reported in the western Atlantic and Caribbean Sea. Low, stable population densities in south Florida suggest there may be a natural mechanism for lionfish population control. In the Dry Tortugas, lionfish density in 2016 was significantly lower $\left(0.6\right.$ ind ha $\left.{ }^{-1} \pm 0.15 \mathrm{SE}\right)$ than the two other south Florida regions. The Dry Tortugas region has the highest percentage of marine protected areas, the lowest level of exploitation, and thus the highest densities of potential lionfish predators and competitors. In the Florida Keys and southeast Florida in 2016, lionfish densities were greater (5.4 ind ha-1 $\pm 1.0 \mathrm{SE}$ and $9.0 \pm 2.7 \mathrm{SE}$, respectively) than the Dry Tortugas. Fishing pressure on lionfish was higher in these two regions, but densities of several potential predators and competitors were substantially lower. Despite relatively low regional lionfish densities that can be attributed to some combination of fishing mortality and natural biocontrol, lionfish are still well established in the south Florida coral reef ecosystem, warranting continued concern. 
2 Regional differences in an established population of invasive Indo-Pacific lionfish (Pterois

5 David R. Bryan ${ }^{1,2, *}$, Jeremiah Blondeau ${ }^{3}$, Ashley Siana ${ }^{1}$ and Jerald. S. Ault ${ }^{1}$

$7 \quad{ }^{1}$ Department of Marine Ecosystems and Society, Rosenstiel School of Marine and Atmospheric

8 Science, University of Miami, Miami, Florida, United States of America

2 Pacific States Marine Fisheries Commission, Alaska Fisheries Science Center, National Marine Fisheries Service, National Oceanic and Atmospheric Administration, Seattle, Washington,

11 United States of America

3 Southeast Fisheries Science Center, National Marine Fisheries Service, National Oceanic and

13 Atmospheric Administration, Miami, Florida, United States of America

*Corresponding author

19 E-mail: david.bryan@noaa.gov (DB) 


\section{Abstract.}

About nine years ago (circa 2009), Indo-Pacific lionfishes (Pterois volitans and P. miles) invaded the south Florida coral reef ecosystem. During the intervening period of time, there has been substantial research on their biology, life history, demography, and habitat preferences; however, little is known concerning their regional population status and trends in the region. Here, we use a large-scale fisheries independent reef fish visual survey to investigate lionfish population status among three south Florida regions: Dry Tortugas, Florida Keys, and southeast Florida. Density estimates (ind ha ${ }^{-1}$ ) have been relatively stable since 2012, and are lower than other areas reported in the western Atlantic and Caribbean Sea. Low, stable population densities in south Florida suggest there may be a natural mechanism for lionfish population control. In the Dry Tortugas, lionfish density in 2016 was significantly lower $\left(0.6\right.$ ind ha $\left.\mathrm{h}^{-1} \pm 0.15 \mathrm{SE}\right)$ than the two other south Florida regions. The Dry Tortugas region has the highest percentage of marine protected areas, the lowest level of exploitation, and thus the highest densities of potential lionfish predators and competitors. In the Florida Keys and southeast Florida in 2016, lionfish densities were greater (5.4 ind ha-1 $\pm 1.0 \mathrm{SE}$ and 9.0 $\pm 2.7 \mathrm{SE}$, respectively) than the Dry Tortugas. Fishing pressure on lionfish was higher in these two regions, but densities of several potential predators and competitors were substantially lower. Despite relatively low regional

37 lionfish densities that can be attributed to some combination of fishing mortality and natural

38 biocontrol, lionfish are still well established in the south Florida coral reef ecosystem, warranting 39 continued concern. 
40 Introduction.

41 Indo-Pacific lionfishes (Pterois volitans and P. miles) are the first non-native marine fish

42 species to become established in the central western Atlantic (Whitfield et al. 2002, Schofield

43 2009). Although there were scattered reports of lionfish in south Florida in the late 1990s and

44 2000s, lionfish were not prominent until 2009, perhaps from a pulse of larval recruits from upstream sources in the Caribbean Sea (Morris 2009, Johnston and Purkis 2011, Ruttenberg et al. 2012). Shortly after the arrival of larval recruits, lionfish became established in south Florida

47 through local reproduction coupled with continued larval recruitment from the eastern Gulf of Mexico, Meso-American, and Cuban reefs (Schofield 2009, Johnston and Purkis 2015).

Following their arrival in south Florida, lionfish occurrence and relative abundance increased dramatically (Ruttenberg et al. 2012).

Broad environmental tolerances, relatively rapid growth and high survivorship of recruits have facilitated explosive population growth of lionfish throughout most of their introduced range (Morris 2009, Claydon et al. 2012, Edwards et al. 2014, Gardner et al. 2015). Lionfish are

54 also highly effective predators capable of consuming large quantities of native fish and crustaceans (Morris and Akins 2009, Muñoz et al. 2011, Green et al. 2012, Côté et al. 2013). Relative to similarly-sized native predators such as snappers and groupers, lionfish can contribute to substantial declines in prey abundance (Albins and Hixon 2008, Albins 2012). The direct effect of these declines are not limited to small-bodied reef fish species, as lionfish also eat the juveniles of larger-bodied mesopredators and grazers, including economically important species such as groupers, snappers, and grunts (Morris and Akins 2009, Côté et al. 2013, Dahl and Patterson 2014). Thus, there is significant concern that lionfish predation on native reef fishes may threaten coral reef ecosystems throughout its introduced range (Albins and Hixon 63 2008, 2013). 
64

65

66

67

68

Most of the research on lionfish has been conducted at relatively small spatial scales, resulting in a dearth of information regarding lionfish population status on a larger regional scale. The southern Florida reef fish visual census (RVC) is an extensive, multi-agency probability-based survey, designed to estimate the size-structured abundance of more than 300 species of tropical coral reef fishes (Brandt et al. 2009, Smith et al. 2011). The RVC has been conducted throughout the south Florida coral reef ecosystem since 1979 and currently includes three regions: Dry Tortugas, Florida Keys, and southeast Florida (Fig 1). Although lionfish appear to have successfully invaded and colonized south Florida (Ruttenberg et al. 2012), there has been scant information on temporal or spatial trends in lionfish population size since their establishment. In this study, we used the RVC data to test hypotheses concerning population trends in lionfish density since their arrival, and whether differences exist among the three south Florida regions. To better understand factors that may control lionfish population size, we investigated density estimates of potential lionfish predators and competitors, and regional differences in fishing intensities.

\section{Materials and methods.}

The RVC is a probability-based stratified random sampling survey used in a collaborative, multi-agency fisheries independent monitoring program that has been conducted since 1979 to obtain size-structured abundance estimates of reef fish populations in south Florida (Brandt et al. 2009, Smith et al. 2011). Beginning in 2014, the RVC was incorporated into the larger National Coral Reef Monitoring Program, and is now one facet of a broader coral reef ecosystem monitoring effort that includes biological trends, climate-driven impacts and socioeconomic connections in the United States. Currently, the RVC is conducted bi-annually in three south Florida regions: (1) Dry Tortugas; (2) Florida Keys; and, (3) southeast Florida (Fig 1). The 
87 spatial domain of the survey encompasses the full extent of mapped coral reef habitats to $35 \mathrm{~m}$ 88 depths in each region.

The RVC uses a two-stage stratified random sampling design to partition the survey areas into subareas (i.e., strata) with varying levels of variance in reef fish density. Environmental features such as bathymetry and benthic habitat types were used to construct regional strata. A sampling frame, consisting of a finite number of non-overlapping primary sampling units (PSUs), was initially created by laying a 200 x $200 \mathrm{~m}$ grid over bathymetry and habitat maps. Recent updates in mapping products have allowed for a smaller $100 \times 100 \mathrm{~m}$ grid to be used in southeast Florida, and in all regions in 2016. Each grid cell, was assigned to a strata based on the underlying habitat type and depth. The number and definition of strata vary between regions, as the Florida reef tract is characterized by a gradual shift in geology and habitat types (Hoffmeister and Multer 1968, Davis 1982, Banks et al. 2007).

The Dry Tortugas region is characterized by a large, relatively deep, western bank with extensive terrace reefs, occasional pinnacles, and ledges (Franklin et al. 2003). The Dry Tortugas region also contains the Dry Tortugas National Park, an atoll-like structure with several shallow water banks, low to medium profile continuous reefs, low and high relief spur and groove formations, and both individual and aggregate patch reefs. In the Dry Tortugas, there are eight different strata comprised of three main habitat types with up to three levels of relief: isolated reefs with high, medium or low relief, continuous reefs with high, medium or low relief and spur and groove reefs with either high or low relief.

The Florida Keys region, which begins $100 \mathrm{~km}$ to the east of the Dry Tortugas, includes 250 groove, back reef and an extensive patch reef system. In the Florida Keys region, there are seven 
110 possible strata. The low relief forereef system is classified by three depth categories $(<6 \mathrm{~m}, 6-18$

$111 \mathrm{~m}$, and $\geq 18 \mathrm{~m}$ ), the patch reef system is classified by location within the reef system (inshore,

112 mid-channel, and offshore), and the last strata includes all high relief spur and groove habitats.

113 At the northern edge of the Florida Keys region, the classic tropical reef system shifts to a

114 sponge and algae dominated reef constituted by several ridges that run parallel to the shoreline.

115 In southeast Florida, there are eight habitat strata divided into low or high relief categories: a

116 deep ridge strata in Martin County, linear reef along the outer reef tract including the deep ridge

117 habitat outside of Martin County, shallow $(<20 \mathrm{~m})$ individual and aggregated patch reefs, deep

$118(>20 \mathrm{~m})$ individual and aggregated patch reefs, a deep ridge complex, linear reef along the

119 middle reef tract, linear reef along the inner reef tract and the shallow ridge.

120 The size-structured abundance of reef fish were collected by trained scuba divers within a 15

$121 \mathrm{~m}$ diameter cylinder (Brandt et al. 2009). A two-stage sampling scheme was employed to

122 account for the disparity in area between a minimum mapping unit $\left(40,000 \mathrm{~m}^{2}\right.$ to $\left.10,000 \mathrm{~m}^{2}\right)$ of

123 each PSU (grid cell) and the area surveyed by each diver $\left(177 \mathrm{~m}^{2}\right)$, the second-stage unit (SSU).

124 Within each PSU there were two SSUs. Because of diving safety concerns, each SSU was

125 sampled by two closely spaced divers. For analysis, a single SSU sample was computed as the

126 arithmetic average of the adjacent fish counts for paired divers.

127 Sample allocation among strata and site selection occured separately for each region. For

128 each survey, a Neyman allocation scheme was used to determine the numbers of PSUs randomly

129 selected for each strata. This scheme accounts for the stratum's size and the standard deviation of

130 density for several key species calculated from previous surveys. Thus, a stratum with a higher

131 variance of fish density received a greater number of samples, as compared to its proportion of

132 the total area in the region. Second-stage units (SSUs) were randomly selected in the field. 
134 random sampling were adapted from Cochran (1977), can be found in Smith et al. (2011), and

135 are as follows: First, the mean density for each PSU $(i)$ in stratum $(h)$ in region $(r)$ was calculated

136 by averaging the SSUs $(j)$,

$$
\bar{D}_{r h i}=\frac{1}{m_{r h i}} \sum_{j} D_{r h i j}
$$

where $m_{h i}$ is the number of SSUs in PSU $i$ in stratum $h$ ). Regional strata density was then calculated as the average of all PSUs in each strata,

$$
\overline{\bar{D}}_{r h}=\frac{1}{n_{r h}} \sum_{i} \bar{D}_{r h i}
$$

where $n_{r h}$ is the number of PSUs in stratum $h$ in region $r$. Finally the region-wide mean density estimate was calculated by summing the regional strata estimates that are weighted by area.

$$
\overline{\bar{D}}_{r}=\sum_{h} W_{r h} \overline{\bar{D}}_{r h}
$$

The regional stratum weighting factor $\left(W_{r h}\right)$ was generated by dividing the number of SSUs in a strata by the total number of SSUs in a region.

$$
w_{r h}=\frac{N_{r h} M_{r h}}{\sum_{r h} N_{r h} M_{r h}}
$$

148 Estimation of variance for mean density began with calculating the sample variance among

149 SSUs,

150

$$
s_{2 r h}^{2}=\frac{1}{n r_{h}} \sum_{i}\left[\frac{\sum_{j}\left(D_{r h i j}-\bar{D}_{r h i}\right)^{2}}{m_{r h i}-1}\right]
$$

151 and the sample variance among PSUs. 


$$
s_{1 r h}^{2}=\frac{\sum_{r i}\left(\overline{\bar{D}}_{r h i}-\overline{\bar{D}}_{r h}\right)^{2}}{n_{r h}-1}
$$

153 Then the variance of mean density was calculated for each strata as

$$
\operatorname{var}\left[\overline{\bar{D}}_{r h}\right]=\frac{\left(1-\frac{n_{r h}}{N_{r h}}\right)}{n_{r h}} s_{1 r h}^{2}+\frac{\frac{n_{r h}}{N_{r h}}\left(1-\frac{\bar{m}_{r h}}{M_{r h}}\right)}{n_{r h} m_{r h}} s_{2 r h}^{2}
$$

155

156

157

158

159

160

161

162

163

164

165

166

167

168

169

170

171

172

and finally, the variance of regional mean density was

$$
\operatorname{var}\left[\overline{\bar{D}}_{r}\right] \sum_{h} w_{r h}^{2} \operatorname{var}\left[\overline{\bar{D}}_{r h}\right]
$$

The standard error (SE) was calculated as the square root of the regional density estimate.

The R package "RVC" was used to make the regional density and variance calculations (Ganz 2015). In the RVC package, density is estimated at the SSU level (ind per $177 \mathrm{~m}^{2}$ ), then converted to ind ha-1 for consistency with most published lionfish research.

Annual estimates of mean lionfish population density were calculated for 2010, 2012, 2014, and 2016 for the Dry Tortugas, 2010, 2011, 2012, 2014, and 2016 for the Florida Keys, and 2012, 2014, 2015, 2016 for southeast Florida. Standard statistical procedures were used to test for differences among years within a region and among regions for each year (Lohr 2010). We constructed $95 \%$ confidence intervals (CI) for each estimate by multiplying the SE of each estimate by the appropriate values of the Student's t-distribution based on a 0.05 probability and the degrees of freedom. The degrees of freedom for a two-stage random sample design were calculated as the total number of SSUs minus the total number of PSUs and total number of strata. CI t-tests were used as they are better suited to sample design statistics and do not require homogenous variance of two distributions to test differences in mean responses. Trends in lionfish density were investigated within each region between years. Regional differences were compared for two regions at a time, by year. A significant difference in lionfish density ( $p$ 
$173<0.05$ ), between paired estimates, was defined as when the mean of one estimate did not fall into

174 the confidence interval of the second estimate, and when the mean of the second estimate did not

175 fall into confidence interval of the first estimate. Samples for the 2012 southeast Florida region

176 were from 2012 and 2013. They were combined, since each year alone did not have enough

177 samples to generate region-wide estimates. Data from 2014 and 2016 were combined, to increase

178 the sample size and to calculate stratum level estimates of lionfish density for each region with a

179 standard error. CI t-tests were used to compare stratum estimates within each region.

180 There are substantial differences in spatial protection of fisheries resources in the three

181 regions. In the Dry Tortugas, $47.4 \%$ of the RVC survey domain is fully protected from fishing,

182 while, in the Florida Keys only $4.4 \%$ of the survey domain is protected. There are no protected

183 areas in the southeast Florida region. These differences, in combination with regional differences

184 in geomorphology and benthic habitat types, can have an effect on the diversity and abundance

185 of respective fish assemblages (Beukers and Jones 1998, Friedlander and Parrish 1998,

186 Gratwicke and Speight 2005). We evaluated the numerical importance of lionfish for each region

187 in south Florida by calculating the individual densities for all reef fish species. A subset of

188 piscivorous species that are potential predators and competitors was also evaluated (S1 Table).

189 The density of potential predators and piscivorous competitors was calculated for six groups for

190 each region. These groups were based on taxa and fish size and included: snappers, jacks, large

191 groupers, small groupers, hamlets, and Serranus spp. Differences in density of these groups

192 among regions were compared with CI t-tests $(\mathrm{p}<0.05)$.

\section{Results.}

194 Since 2010, a total of 9,418 paired diver RVC surveys were conducted (Table 1). During this

195 time, 1,663 lionfish were seen. There was no clear temporal trend in regional population density. 
196 Lionfish density in the Dry Tortugas was significantly greater in $2012\left(2.2\right.$ ind ha $\left.^{-1} \pm 0.5 \mathrm{SE}\right)$ and $1972014\left(2.6\right.$ ind $\left.h^{-1} \pm 0.6 \mathrm{SE}\right)$ than in $2010\left(0.4\right.$ ind $\left.\mathrm{ha}^{-1} \pm 0.3 \mathrm{SE}\right)$, but in 2016 it declined to 0.6 198 ind ha ${ }^{-1}( \pm 0.15 \mathrm{SE})$ (Fig 2$)$. In the Florida Keys, density initially increased following the invasion 199 to 6.5 ind ha-1 $( \pm 1.2 \mathrm{SE})$ in 2011 , declined significantly during 2012 and 2014, and then 200 increased slightly to 5.3 ind ha-1 $( \pm 1.0 \mathrm{SE})$ in 2016 . Despite some fluctuations in density, there 201 was no trend in the southeast Florida region since the survey began in 2012. Density in the 202 southeast Florida region was significantly greater in 2012 (8.0 ind ha-1 $\pm 1.2 \mathrm{SE})$ and in 2016 (9.0 203 ind ha- $\left.\mathrm{h}^{-1} \pm 2.7 \mathrm{SE}\right)$ than in 2014 and $2015\left(5.0\right.$ ind $\mathrm{ha}^{-1} \pm 1.0 \mathrm{SE}, 5.1$ ind ha-1 $\pm 1.2 \mathrm{SE}$, 204 respectively). There were significant differences among regions, with lionfish density

205

206

207

208

209

210

211

212

213

214

215

216

217 218

significantly lower in the Dry Tortugas than the southeast Florida region in 2012, 2014 and 2016. Dry Tortugas densities were also lower than the Florida Keys in 2012 and 2016. Lionfish density was significantly lower in the Florida Keys than southeast Florida in 2012, but there were no significant difference in 2014 and 2016 (Fig 2).

There were differences in lionfish densities amongst strata within each region (Fig 3). In the Dry Tortugas, isolated high relief strata had the highest density (11.1 ind ha $\left.{ }^{-1} \pm 1.6 \mathrm{SE}\right)$, and in general, higher relief strata had greater densities of lionfish. In the Florida Keys, the highest density was within the deep forereef strata (17.4 ind ha-1 $\pm 3.8 \mathrm{SE})$ and densities in the other strata were similar. In southeast Florida, lionfish densities were the highest within the high and low relief deep ridge strata (51.5 ind ha-1 $\pm 14.3 \mathrm{SE}$ and 32.3 ind ha- $\mathrm{ha}^{-1} \pm 23.4 \mathrm{SE}$, respectively), but were also high $\left(>10\right.$ ind ha- $\left.{ }^{-1}\right)$ in other deep offshore strata. The strata with high densities of lionfish often comprised a minor proportion habitat in each region. For example, in the Dry Tortugas the isolated high relief strata with the highest density of lionfish made up only $2.5 \%$ of the hardbottom habitat in the survey domain (Fig 3). In the Florida Keys, the deep forereef strata, 
219 which had the highest density of lionfish, made up $14.2 \%$ of the hardbottom habitat. In southeast

220 Florida, the high and low relief deep ridge strata, which had the highest densities of lionfish, only

221 represented $0.5 \%$ and $2.6 \%$ percent of hardbottom habitat in the survey, respectively.

222 In 2016, there were 133 species of fish in the Dry Tortugas with a greater abundance than

223 lionfish out of total of 236 species observed. In the Florida Keys and southeast Florida, where

224251 species were observed in 2016 , lionfish were the $95^{\text {th }}$ and $78^{\text {th }}$ most abundant fish,

225 respectively. Lionfish were the $30^{\text {th }}$ most abundant piscivore in the Dry Tortugas out of 66

226 observed, $17^{\text {th }}$ out of 66 in the Florida Keys, and $13^{\text {th }}$ out of 68 in southeast Florida (Fig 4). The

227 densities of competitors and predators varied among regions, but in general, densities were

228 higher in the Dry Tortugas. The Dry Tortugas had a significantly greater density of snappers

229 (Lutjanidae), hamlets (Hypoplectrus spp.), and large groupers (Serranidae) than both the Florida

230 Keys and southeast Florida (Fig 5). There were significantly more Serranus spp. than the Florida

231 Keys and small groupers than southeast Florida. The Florida Keys had a significantly greater

232 density of small groupers than the other two regions, and more snappers and hamlets than

233 southeast Florida. There was no differences in the densities of jacks among regions. Combined,

234 there were 1041.0, 896.8, and 450.7 ind ha ${ }^{-1}$ of competitors and predators from these groups in

235 the Dry Tortugas, Florida Keys and southeast Florida regions, respectively.

\section{Discussion.}

237 Following the initial increase in density after their 2009 invasion, lionfish populations in

238 south Florida appear to have reached a relatively stable plateau within the coral reef fish

239 community. Regional lionfish density estimates were generally lower in south Florida than those

240 reported for other invaded areas using similar visual survey techniques: Belize, 160 ind ha $^{-1}$

241 (Hackerott et al. 2013); Cuba, 150 ind ha-1 (Hackerott et al. 2013); Little Cayman Island, 21.5- 
242162.5 ind ha-1 (Bejarano et al. 2014); North Carolina, 84.6 ind ha ${ }^{-1}$ (Whitfield et al. 2014);

243 Panama, 300 ind ha-1 (Palmer et al. 2016); and Venezuela, 30-121 ind ha-1 (Elise et al. 2015).

244 The south Florida estimates were similar to densities in their native range: Indian Ocean, 3.6 ind

$245 \mathrm{ha}^{-1}$ and Pacific Ocean, 0.27 ind ha-1 (Kulbicki et al. 2012). This combination of low and stable

246 densities suggests that there may be some combination of factors negatively influencing lionfish

247 populations in south Florida. The factors controlling invasive lionfish are still unclear (Benkwitt

248 et al. 2017), and likely depend on the area in question (Barbour et al. 2011, Mumby et al. 2011,

249 Frazer et al. 2012, Hackerott et al. 2013, Johnston and Purkis 2015). Two principal mechanisms

250 for potential lionfish population control, directed fishing and predation, have been widely

251 discussed in the scientific literature since their introduction into the central western Atlantic and

252 Caribbean Sea (Barbour et al. 2011, Mumby et al. 2011, Hackerott et al. 2013, Smith et al.

253 2017). Divers and fishers have become adept at catching lionfish, and while studies have shown

254 some localized benefits, the broader ecosystem impacts of lionfish exploitation are less clear

255 (Barbour et al. 2011, Frazer et al. 2012, Green et al. 2014, Smith et al. 2017). The effect of

256 predatory biocontrol to invasive perturbations has been much disputed in the literature, where

257 some areas showed an apparent inverse relationship between predators and lionfish (Mumby et

258 al. 2011), while others showed no response (Hackerott et al. 2013, Valdivia et al. 2014). Much of

259 the discussion has been centered on the population effects of large predators on adult lionfish.

260 However, predation or competition at an earlier life stages may have a greater influence on

261 lionfish abundance (Shulman and Ogden 1987, Hixon 1991, Carr and Hixon 1995, Almany and

262 Webster 2006).

263 The RVC data, designed to provide population-level estimates of reef fish densities, provide

264 a broad, regional perspective on the lionfish invasion in comparison to site or sample-specific 
265 estimates commonly found in the literature. Furthermore, differences amongst the south Florida

266 regions can give further insight into the mechanisms controlling their population. Due to its

267 remote location and numerous large marine protected areas, overall fishing pressure is minimal

268 in the Dry Tortugas, which has resulted in a greater biomass of exploited snapper and grouper

269 species (Ault et al. 2013), along with a very low fishing mortality rate of lionfish. This is in

270 contrast to the Florida Keys and southeast Florida, where fishing pressure on native reef fishes is

271 extremely high, snapper and grouper populations are overfished (Ault et al. 2005), and divers

272 target lionfish both recreationally and commercially (Harvey and Mazzotti 2016). In addition to

273 greater numbers of large exploited groupers and snappers in the Dry Tortugas, we also found that

274 hamlets and other small serranids (Serranus spp.) were more abundant. These small carnivorous

275 fishes have diets that overlap with juvenile and adult lionfish and may be direct competitors

276 during all life stages (Randall 1967, Whiteman et al. 2007, Côté et al. 2013). Some of these

277 potential competitors are piscivorous and may consume lionfish while they are juveniles.

278 Survival of juvenile fish is partly determined by the suite of predators occurring at the site of

279 settlement (Holmes and McCormick 2010), and early post-settlement mortality through

280 predation is a major driver of reef fish community structure (Hixon 1991, Carr and Hixon 1995,

281 Almany and Webster 2006). Small, active predators have high metabolic and consumption rates

282 which can have a dramatic effect on recently settled juvenile fishes, and hence, a

283 disproportionally large influence on fish assemblages within their range (Feeney et al. 2012).

284 From a biological control perspective, it is likely that lionfish populations are more impacted at

285 the early settlement stage from predation than compared to their adult life stage.

286 In the Florida Keys and southeast Florida, where large piscivores are largely extirpated (Ault

287 et al. 2005) and hamlets are rare, fishing mortality may play a larger role in the control of 
288 lionfish populations. Although the amount of directed fishing effort and removals of lionfish

289 through the recreational fishery are not well measured, estimated landings in Florida have

290 increased exponentially from 1,040 kg in 2010 to 309,883 kg in 2017 (NMFS, 2018a).

291 Numerous national and local public awareness campaigns have raised awareness on the

292 importance of lionfish removal throughout Florida (Harvey and Mazzotti 2016), presumably

293 leading to greater directed fishing efforts on lionfish. In addition to increased mortality from

294 recreational fishers, the commercial fishery for lionfish in Florida has also grown significantly

295 from $1,080 \mathrm{~kg}$ in 2011 to 49,553 $\mathrm{kg}$ in 2016 and valued at over \$530,000 dollars (NMFS, 2018b).

296 Although fishing mortality has not been high enough to eradicate lionfish (Barbour et al. 2011),

297 it appears that in conjunction with potential natural biocontrols, it has been effective in

298 stabilizing lionfish populations in the Florida Keys.

299 Two other factors that could influence the regional differences in lionfish density are habitat

300 availability and local recruitment processes. Although lionfish have been recorded in a wide

301 range of environments (Barbour et al. 2010, Jud et al. 2011, Pimiento et al. 2015), some research

302 suggests a preference for deeper, higher complexity habitats in invaded reefs (Biggs and Olden

303 2011, Claydon et al. 2012). This preference was also observed in south Florida, but the

304 stratification scheme used to optimize the RVC estimates was not conducive for regional

305 comparisons in habitat availability since strata within each region are classified differently and

306 often are comprised of several habitat types. For example, the strata in the Florida Keys are

307 based on depth, distance from shoreline, and habitat configuration (continuous versus patchy);

308 thus they do not include explicit information on relief or complexity at each site. In the Dry

309 Tortugas, relief and habitat configuration are used to define strata, but depth is not used. In the

310 southeast Florida region, complexity, depth, and habitat configuration is used. Despite these 
311 differences in defining characteristics, roughly $25 \%$ of each region is comprised of a

312 combination of strata that contain deep and either high relief or high complexity reefs that are

313 preferred by adult lionfish. Given this large amount of available habitat, it is unlikely that

314 lionfish populations are limited by habitat in any region.

315 Reef fish larval transport and subsequent recruitment in the Dry Tortugas, Florida Keys, and

316 southeast Florida region is largely driven by the Florida Current and its associated eddies (Lee et

317 al. 1992, Sponaugle et al. 2005). All three regions are highly connected and local retention of

318 larvae plays a major role in recruitment of reef fish (Lee et al. 1994, Sponaugle et al. 2012,

319 Bryan et al. 2015) with limited sources of recruits entering the region from the Caribbean and

320 Gulf of Mexico through the Loop Current (Roberts 1997, Paris et al. 2005, Bryan et al. 2015).

321 There has been no study looking at differences in recruitment rates between the three RVC

322 regions and previous work on lionfish larval transport has grouped them together (Johnston and

323 Purkis 2015, Johnston et al. 2017). Since regional rates of lionfish recruitment are unknown, it

324 cannot be ruled out as a possible factor influencing the differences in density.

Although lionfish populations in south Florida appear to have stabilized, their successful colonization could still have major direct and indirect impacts on the local fish community in the top $10 \%$ for piscivores in the southeast Florida region, and in the top $25 \%$ in the Dry Tortugas and the Florida Keys. Currently it is unknown if their establishment in south Florida has caused a regional shift in the fish community. In other invaded areas off the southeastern coast of the United States, where lionfish densities are greater, there has been a regional

332 reduction in the native tomtate population (Ballew et al. 2016), whereas on the Belize Barrier

333 Reef no effect on prey species was observed (Hackerott et al. 2017). Additional analysis utilizing 
334 current and future RVC data may be useful to determine if lionfish have had any effect on local

335 reef fish communities in south Florida.

336 It is also important to note that while the RVC survey domain covers a large extent of

337 lionfish habitat in south Florida, it is possible that trends in lionfish density are different in 338 waters deeper than $35 \mathrm{~m}$, or in shallow seagrass or mangrove habitats. Lionfish have been 339 commonly found on mesophotic reefs (40-150 m) in the Gulf of Mexico and Bahamas (Lesser 340 and Slattery 2011, Nuttall 2014), and are anecdotally common on deep reefs and artificial 341 structures throughout south Florida, but little is known of their density or possible trends in 342 abundance. Standardized surveys of mesophotic and artificial reefs would provide valuable 343 information to further understand the population status of lionfish in south Florida.

\section{Conclusion.}

345 Lionfish have become an established predator in the south Florida reef fish community. The 346 population density has been relatively stable along the south Florida coral reef tract in waters less 347 than $35 \mathrm{~m}$ depth. Relatively low and stable density estimates suggests a mechanism for 348 population control in south Florida. In the Dry Tortugas, where lionfish densities are lowest, 349 fishing pressure is minimal but predators and competitors are more abundant, suggesting that 350 lionfish population density may be naturally controlled. In the Florida Keys and southeast

351 Florida, fishing pressure is extremely high, and the resultant density of predators and competitors 352 is only slightly lower, implying that a combination of fishing mortality and biocontrols may be 353 constraining lionfish population growth. 
354 Acknowledgements.

355 The RVC reef fish visual census is a long term and large scale monitoring effort that has only

356 been possible through extensive partnerships and collaboration involving a number of federal

357 and state agencies and institutions: NOAA's Southeast Fisheries Science Center, University of

358 Miami, National Park Service, Florida Fish and Wildlife Conservation Commission, and Nova

359 Southeastern University. We greatly appreciate the contributions of literally hundreds of

360 scientific divers that have participated in the program since its inception. We thanks Steven G.

361 Smith for statistical support and Harry Ganz for creating the R open source code RVC package

362 used here for analyses.

363

364 References.

365

366

367

368

369

370

371

372

373

374

375

376

377

378

379

380

Albins, M. A. 2012. Effects of invasive Pacific red lionfish Pterois volitans versus a native predator on Bahamian coral-reef fish communities. Biological Invasions 15:29-43.

Albins, M. A., and M. A. Hixon. 2008. Invasive Indo-Pacific lionfish Pterois volitans reduce recruitment of Atlantic coral-reef fishes. Marine Ecology Progress Series 367:233-238.

Albins, M. A., and M. A. Hixon. 2013. Worst case scenario: potential long-term effects of invasive predatory lionfish (Pterois volitans) on Atlantic and Caribbean coral-reef communities. Environmental Biology of Fishes 96:1151-1157.

Almany, G. R., and M. S. Webster. 2006. The predation gauntlet: early post-settlement mortality in reef fishes. Coral Reefs 25:19-22.

Ault, J., S. Smith, and J. Bohnsack. 2005. Evaluation of average length as an estimator of exploitation status for the Florida coral-reef fish community. ICES Journal of Marine Science 62:417-423.

Ault, J. S., S. G. Smith, J. A. Bohnsack, J. Luo, N. Zurcher, D. B. McClellan, T. A. Ziegler, D. E. Hallac, M. Patterson, M. W. Feeley, B. I. Ruttenberg, J. Hunt, D. Kimball, and B. Causey. 2013. Assessing coral reef fish population and community changes in response to marine reserves in the Dry Tortugas, Florida, USA. Fisheries Research 144:28-37. 
381

382

383

384

385

386

387

388

389

390

391

392

393

394

395

396

397

398

399

400

401

402

403

404

405

406

407

408

409

410

Ballew, N. G., N. M. Bacheler, G. T. Kellison, and A. M. Schueller. 2016. Invasive lionfish reduce native fish abundance on a regional scale. Scientific Reports 6:32169.

Banks, K. W., B. M. Riegl, E. A. Shinn, W. E. Piller, and R. E. Dodge. 2007. Geomorphology of the southeast Florida continental reef tract (Miami-Dade, Broward, and Palm Beach counties, USA). Coral Reefs 26:617-633.

Barbour, A. B., M. S. Allen, T. K. Frazer, and K. D. Sherman. 2011. Evaluating the potential efficacy of invasive lionfish (Pterois volitans) removals. PLoS ONE 6:e19666.

Barbour, A. B., M. L. Montgomery, A. A. Adamson, E. Díaz-Ferguson, and B. R. Silliman. 2010. Mangrove use by the invasive lionfish Pterois volitans. Marine Ecology Progress Series 401:291-294.

Bejarano, S., K. Lohr, S. Hamilton, and C. Manfrino. 2014. Relationships of invasive lionfish with topographic complexity, groupers, and native prey fishes in Little Cayman. Marine Biology 162:253-266.

Benkwitt, C. E. 2015. Non-linear effects of invasive lionfish density on native coral-reef fish communities. Biological Invasions 17:1383-1395.

Benkwitt, C. E., M. A. Albins, K. L. Buch, K. E. Ingeman, T. L. Kindinger, T. J. Pusack, C. D. Stallings, and M. A. Hixon. 2017. Is the lionfish invasion waning? Evidence from The Bahamas. Coral Reefs 36:1255-1261.

Beukers, J. S., and G. P. Jones. 1998. Habitat complexity modifies the impact of piscivores on a coral reef fish population. Oecologia 114:50-59.

Biggs, C. R., and J. D. Olden. 2011. Multi-scale habitat occupancy of invasive lionfish (Pterois volitans) in coral reef environments of Roatan, Honduras. Aquatic Invasions 6:447-453.

Black, A. N., S. R. Weimann, V. E. Imhoff, M. L. Richter, and M. Itzkowitz. 2014. A differential prey response to invasive lionfish, Pterois volitans: Prey naiveté and risk-sensitive courtship. Journal of Experimental Marine Biology and Ecology 460:1-7.

Brandt, M. E., N. Zurcher, A. Acosta, J. S. Ault, J. A. Bohnsack, M. W. Feeley, D. E. Harper, J. H. Hunt, G. T. Kellison, D. B. McClellan, M. E. Patterson, and S. G. Smith. 2009. Cooperative multi-agency reef fish monitoring protocol for the Florida Keys coral reef ecosystem. Natural Resource Report NPS/SFCN/NRR - 2009/150. National Park Service, Fort Collins, CO. 
411 Bryan, D. R., J. Luo, J. S. Ault, D. B. McClellan, S. G. Smith, D. Snodgrass, and M. F. Larkin.

412

413

414

415

416

417

418

419

420

421

422

423

424

425

426

427

428

429

430

431

432

433

434

435

436

437

438

439

440 2015. Transport and connectivity modeling of larval permit from an observed spawning aggregation in the Dry Tortugas, Florida. Environmental Biology of Fishes 98:22632276.

Carr, M. H., and M. A. Hixon. 1995. Predation effects on early post-settlement survivorship of coral-reef fishes. Marine Ecology Progress Series 124:31-42.

Claydon, J. A. B., M. C. Calosso, and S. B. Traiger. 2012. Progression of invasive lionfish in seagrass, mangrove and reef habitats. Marine Ecology Progress Series 448:119-129.

Cochran, W. G. 1977. Sampling Techniques. 3rd ed. edition. John Wiley and Sons, New York.

Côté, I. M., S. J. Green, J. A. Morris, J. L. Akins, and D. Steinke. 2013. Diet richness of invasive Indo-Pacific lionfish revealed by DNA barcoding. Marine Ecology Progress Series 472:249-256.

Dahl, K. A., and W. F. Patterson. 2014. Habitat-specific density and diet of rapidly expanding invasive red lionfish, Pterois volitans, populations in the Northern Gulf of Mexico. PLoS ONE 9:e105852.

Davis, G. E. 1982. A century of natural change in coral distribution at the Dry Tortugas: a comparison of reef maps from 1881 and 1976. Bulletin of Marine Science 32:608-623.

Edwards, M. A., T. K. Frazer, and C. A. Jacoby. 2014. Age and growth of invasive lionfish (Pterois spp.) in the Caribbean Sea, with implications for management. Bulletin of Marine Science 90:953-966.

Elise, S., I. Urbina-Barreto, H. Boadas-Gil, M. Galindo-Vivas, and M. Kulbicki. 2015. No detectable effect of lionfish (Pterois volitans and P. miles) invasion on a healthy reef fish assemblage in Archipelago Los Roques National Park, Venezuela. Marine Biology 162:319-330.

Feeney, W. E., O. M. Lönnstedt, Y. Bosiger, J. Martin, G. P. Jones, R. J. Rowe, and M. I. McCormick. 2012. High rate of prey consumption in a small predatory fish on coral reefs. Coral Reefs 31:909-918.

Franklin, E.C., J.S. Ault, S.G. Smith, J. Luo, G. A. Meester, G.A. Diaz, M. Chiappone, D.W. Swanson, S.L. Miller, J.A. Bohnsack. 2003. Benthic habitat mapping in the Tortugas region, Florida. Marine Geodesy 26: 19-34. 
441 Frazer, T. K., C. A. Jacoby, M. A. Edwards, S. C. Barry, and C. M. Manfrino. 2012. Coping with

442

443

444

445

446

447

448

449

450

451

452

453

454

455

456

457

458

459

460

461

462

463

464

465

466

467

468

469

470

471

the lionfish invasion: Can targeted removals yield beneficial effects? Reviews in Fisheries Science 20:185-191.

Friedlander, A. M., and J. D. Parrish. 1998. Habitat characteristics affecting fish assemblages on a Hawaiian coral reef. Journal of Experimental Marine Biology and Ecology 224:1-30.

Ganz, H. 2015. A statistical package for the Reef Visual Census. https://rdrr.io/github/harryganz/rvc/

Gardner, P. G., T. K. Frazer, C. A. Jacoby, and R. P. E. Yanong. 2015. Reproductive biology of invasive lionfish (Pterois spp.). Frontiers in Marine Science 2:1-10.

Gratwicke, B., and M. Speight. 2005. The relationship between fish species richness, abundance and habitat complexity in a range of shallow tropical marine habitats. Journal of Fish Biology 66:650-667.

Green, S. J., J. L. Akins, A. Maljković, and I. M. Côté. 2012. Invasive lionfish drive Atlantic coral reef fish declines. PLoS ONE 7:e32596.

Green, S. J., N. K. Dulvy, A. M. L. Brooks, J. L. Akins, A. B. Cooper, S. Miller, and I. M. Côté. 2014. Linking removal targets to the ecological effects of invaders: a predictive model and field test. Ecological Applications 24:1311-1322.

Hackerott, S., A. Valdivia, C. E. Cox, N. J. Silbiger, and J. F. Bruno. 2017. Invasive lionfish had no measurable effect on prey fish community structure across the Belizean Barrier Reef. PeerJ 5:e3270.

Hackerott, S., A. Valdivia, S. J. Green, I. M. Côté, C. E. Cox, L. Akins, C. A. Layman, W. F. Precht, and J. F. Bruno. 2013. Native predators do not influence invasion success of pacific lionfish on Caribbean reefs. PLoS ONE 8:e68259.

Harvey, R. G., and F. J. Mazzotti. 2016. Public Knowledge, Attitudes, and Behaviors toward Invasive Lionfish: Pre-and Post-Campaign Surveys. Final Report to the Florida Fish and Wildlife Conservation Commission. March 2016. 42 pages.

Hixon, M. A. 1991. Predation as a process structuring coral reef fish communities. Pages 475507 in P. F. Sale, editor. The ecology of fishes on coral reefs. Cambridge University Press.

Hoffmeister, J. E., and H. G. Multer. 1968. Geology and origin of the Florida Keys. Geological Society of America Bulletin 79:1487-1502.

Peer] reviewing PDF | (2018:05:28445:2:0:NEW 23 Aug 2018) 
472 Holmes, T. H., and M. I. McCormick. 2010. Size-selectivity of predatory reef fish on juvenile 473 prey. Marine Ecology Progress Series 399:273-283.

474

475

476

477

478

479

480

481

482

483

484

485

486

487

488

489

490

491

492

493

494

495

496

497

498

499

500

501

502

Johnston, M. W., A. M. Bernard, and M. S. Shivji. 2017. Forecasting lionfish sources and sinks in the Atlantic: are Gulf of Mexico reef fisheries at risk? Coral Reefs 36:169-181.

Johnston, M. W., and S. J. Purkis. 2011. Spatial analysis of the invasion of lionfish in the western Atlantic and Caribbean. Marine Pollution Bulletin 62:1218-1226.

Johnston, M. W., and S. J. Purkis. 2015. A coordinated and sustained international strategy is required to turn the tide on the Atlantic lionfish invasion. Marine Ecology Progress Series 533:219-235.

Jud, Z. R., C. A. Layman, J. A. Lee, and D. A. Arrington. 2011. Recent invasion of a Florida (USA) estuarine system by lionfish Pterois volitans/P. miles. Aquatic Biology 13:21-26.

Kindinger, T. L., and M. A. Albins. 2017. Consumptive and non-consumptive effects of an invasive marine predator on native coral-reef herbivores. Biological Invasions 19:131146.

Kulbicki, M., J. Beets, P. Chabanet, K. Cure, E. Darling, S. R. Floeter, R. Galzin, A. Green, M. Harmelin-Vivien, M. Hixon, Y. Letourneur, T. L. de Loma, T. McClanahan, J. McIlwain, G. MouTham, R. Myers, J. K. O’Leary, S. Planes, L. Vigliola, and L. Wantiez. 2012. Distributions of Indo-Pacific lionfishes Pterois spp. in their native ranges: implications for the Atlantic invasion. Marine Ecology Progress Series 446:189-205.

Lee, T. N., M. Clarke, E. Williams, A. F. Szmant, and T. Berger. 1994. Evolution of the Tortugas Gyre and its influence on recruitment in the Florida Keys. Bulletin of Marine Science 54:621-646.

Lee, T. N., C. Rooth, E. Williams, M. McGowan, A. F. Szmant, and M. Clarke. 1992. Influence of Florida Current, gyres and wind-driven circulation on transport of larvae and recruitment in the Florida Keys coral reefs. Continental Shelf Research 12:971-1002.

Lesser, M. P., and M. Slattery. 2011. Phase shift to algal dominated communities at mesophotic depths associated with lionfish (Pterois volitans) invasion on a Bahamian coral reef. Biological Invasions 13:1855-1868.

Lohr, S. L. 2010. Sampling: desing and analysis. 2nd edition. Brooks/Cole, Boston.

Morris, J. A., and J. L. Akins. 2009. Feeding ecology of invasive lionfish (Pterois volitans) in the Bahamian archipelago. Environmental Biology of Fishes 86:389-398. 
503 Morris, J. A. J. 2009. The biology and ecology of the invasive Indo-Pacific lionfish.

504 Mumby, P. J., A. R. Harborne, and D. R. Brumbaugh. 2011. Grouper as a natural biocontrol of 505 invasive lionfish. PLoS ONE 6:e21510.

506 Muñoz, R. C., C. A. Currin, and P. E. Whitfield. 2011. Diet of invasive lionfish on hard bottom 507 reefs of the Southeast USA: insights from stomach contents and stable isotopes. Marine 508 Ecology Progress Series 432:181-193.

509 National Marine Fisheries Service (2018a). Marine recreational information program.

510 https://www.st.nmfs.noaa.gov/recreational-fisheries/index (accessed 16 August 2018)

511 National Marine Fisheries Service (2018b). Commercial fisheries statistics.

512 https://www.st.nmfs.noaa.gov/commercial-fisheries/commercial-landings/annual-

513 landings/index (accessed 16 August 2018)

514 Nuttall, M. 2014. Lionfish (Pterois volitans [Linnaeus, 1758] and P. miles [Bennett, 1828])

515 records within mesophotic depth ranges on natural banks in the Northwestern Gulf of

516 Mexico. BioInvasions Records 3:111-115.

517 Palmer, G., J. D. Hogan, B. D. Sterba-Boatwright, and R. D. Overath. 2016. Invasive lionfish

518 Pterois volitans reduce the density but not the genetic diversity of a native reef fish.

519 Marine Ecology Progress Series 558:223-234.

520 Paris, C. B., R. K. Cowen, R. Claro, and K. C. Lindeman. 2005. Larval transport pathways from

521 Cuban snapper (Lutjanidae) spawning aggregations based on biophysical modeling.

$522 \quad$ Marine Ecology Progress Series 296:93-106.

523 Pimiento, C., J. C. Nifong, M. E. Hunter, E. Monaco, and B. R. Silliman. 2015. Habitat use 524 patterns of the invasive red lionfish P terois volitans: a comparison between mangrove 525 and reef systems in S an S alvador, B ahamas. Marine Ecology 36:28-37.

526 Randall, J. E. 1967. Food habits of reef fishes of the West Indies. Studies in Tropical 527 Oceanography 5:665-847.

528 Roberts, C. M. 1997. Connectivity and management of Caribbean coral reefs. Science 278:1454$529 \quad 1457$.

530 Ruttenberg, B. I., P. J. Schofield, J. L. Akins, A. Acosta, M. W. Feeley, J. Blondeau, S. G. Smith, 531 and J. S. Ault. 2012. Rapid invasion of Indo-Pacific lionfishes (Pterois volitans and 532 Pterois miles) in the Florida Keys, USA: Evidence from multiple pre- and post-invasion 533 data sets. Bulletin of Marine Science 88:1051-1059. 
534 Sancho, G., P. R. Kingsley-Smith, J. A. Morris, C. A. Toline, V. McDonough, and S. M. Doty.

535 2018. Invasive Lionfish (Pterois volitans/miles) feeding ecology in Biscayne National

536 Park, Florida, USA. Biological Invasions 20:2343-2361.

537 Schofield, P. 2009. Geographic extent and chronology of the invasion of non-native lionfish

538 (Pterois volitans [Linnaeus 1758] and P. miles [Bennett 1828]) in the Western North

539 Atlantic and Caribbean Sea. Aquatic Invasions 4:473-479.

540 Shulman, M., and J. Ogden. 1987. What controls tropical reef fish populations: recruitment or

541 benthic mortality? An example in the Caribbean reef fish Haemulon flavolineatum.

542 Marine Ecology Progress Series:233-242.

543 Smith, N. S., S. J. Green, J. L. Akins, S. Miller, and I. M. Côté. 2017. Density-dependent

544 colonization and natural disturbance limit the effectiveness of invasive lionfish culling

545 efforts. Biological Invasions 19:2385-2399.

546 Smith, S. G., J. S. Ault, J. A. Bohnsack, D. E. Harper, J. Luo, and D. B. McClellan. 2011.

547 Multispecies survey design for assessing reef-fish stocks, spatially explicit management

548 performance, and ecosystem condition. Fisheries Research 109:25-41.

549 Sponaugle, S., T. Lee, V. Kourafalou, and D. Pinkard. 2005. Florida Current frontal eddies and

550 the settlement of coral reef fishes. Limnology and Oceanography 50:1033-1048.

551 Sponaugle, S., C. Paris, K. Walter, V. Kourafalou, and E. Alessandro. 2012. Observed and

552 modeled larval settlement of a reef fish to the Florida Keys. Marine Ecology Progress

553 Series 453:201-212.

554 Valdivia, A., J. F. Bruno, C. E. Cox, S. Hackerott, and S. J. Green. 2014. Re-examining the

555 relationship between invasive lionfish and native grouper in the Caribbean. PeerJ 2:e348.

556 Whiteman, E., I. Côté, and J. Reynolds. 2007. Ecological differences between hamlet

557 (Hypoplectrus: Serranidae) colour morphs: between-morph variation in diet. Journal of

558 fish biology 71:235-244.

559 Whitfield, P. E., T. Gardner, S. P. Vives, M. R. Gilligan, W. R. Courtenay Ray, G. C. Ray, and J.

560 A. Hare. 2002. Biological invasion of the Indo-Pacific lionfish Pterois volitans along the

561 Atlantic coast of North America. Marine Ecology Progress Series 235:289-297.

562 Whitfield, P. E., R. C. Muñoz, C. A. Buckel, B. P. Degan, D. W. Freshwater, and J. A. Hare.

563 2014. Native fish community structure and Indo-Pacific lionfish Pterois volitans densities 
564 along a depth-temperature gradient in Onslow Bay, North Carolina, USA. Marine

565 Ecology Progress Series 509:241-254.

566

567 
Figure 1

Map of south Florida regions.

(A) Dry Tortugas; (B) Florida Keys; and, (C) southeast Florida. Locations of RVC surveys and observed lionfish abundance at each secondary sampling unit during 2014 and 2016 surveys.

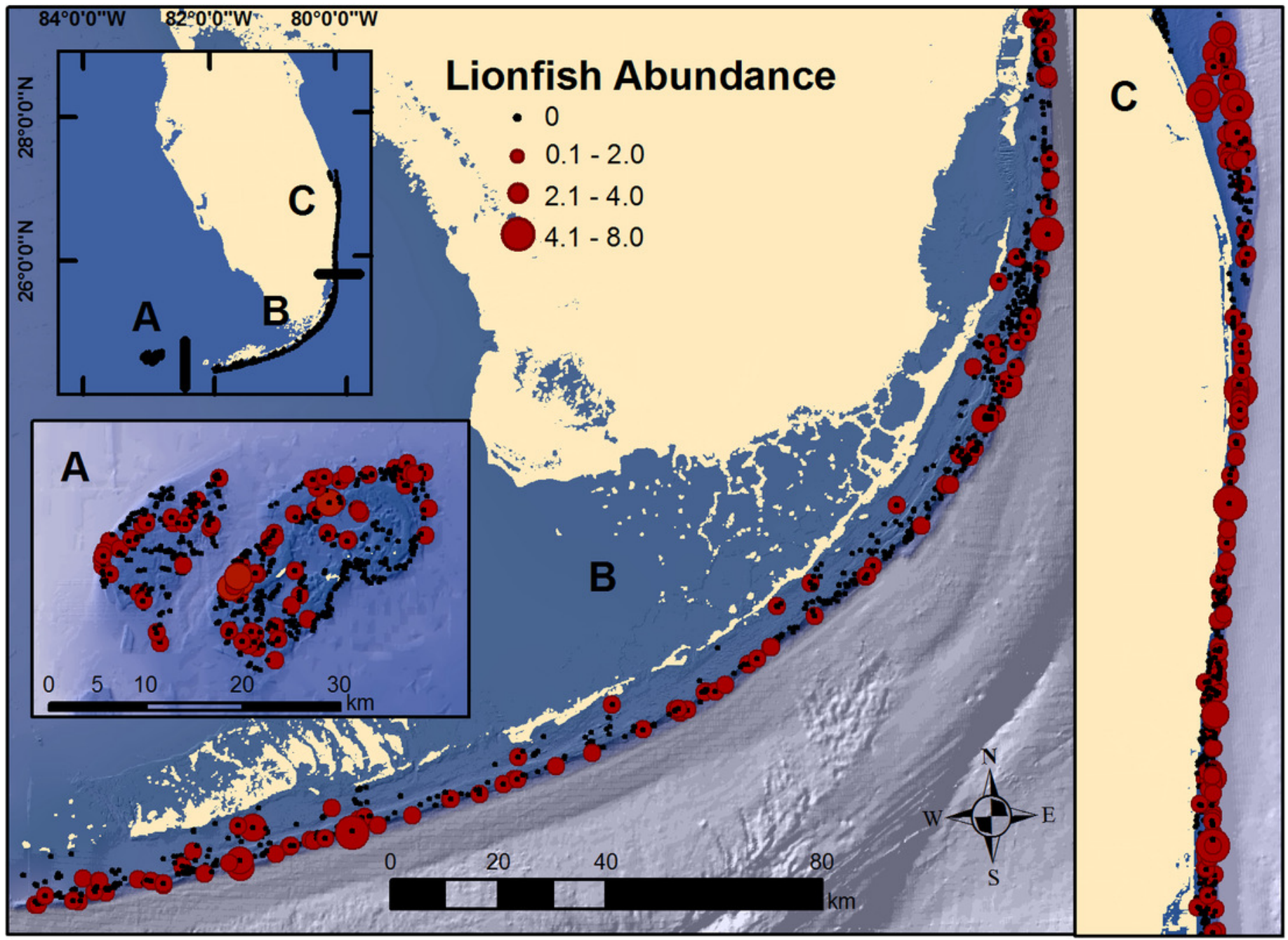


Figure 2

Lionfish population level density estimates (ind ha ${ }^{-1}$ ) by region from 2008 through 2016.

Bars show 95\% confidence intervals.

$\rightarrow$ Dry Tortugas - - Florida Keys $-\longrightarrow$ - Southeast Florida

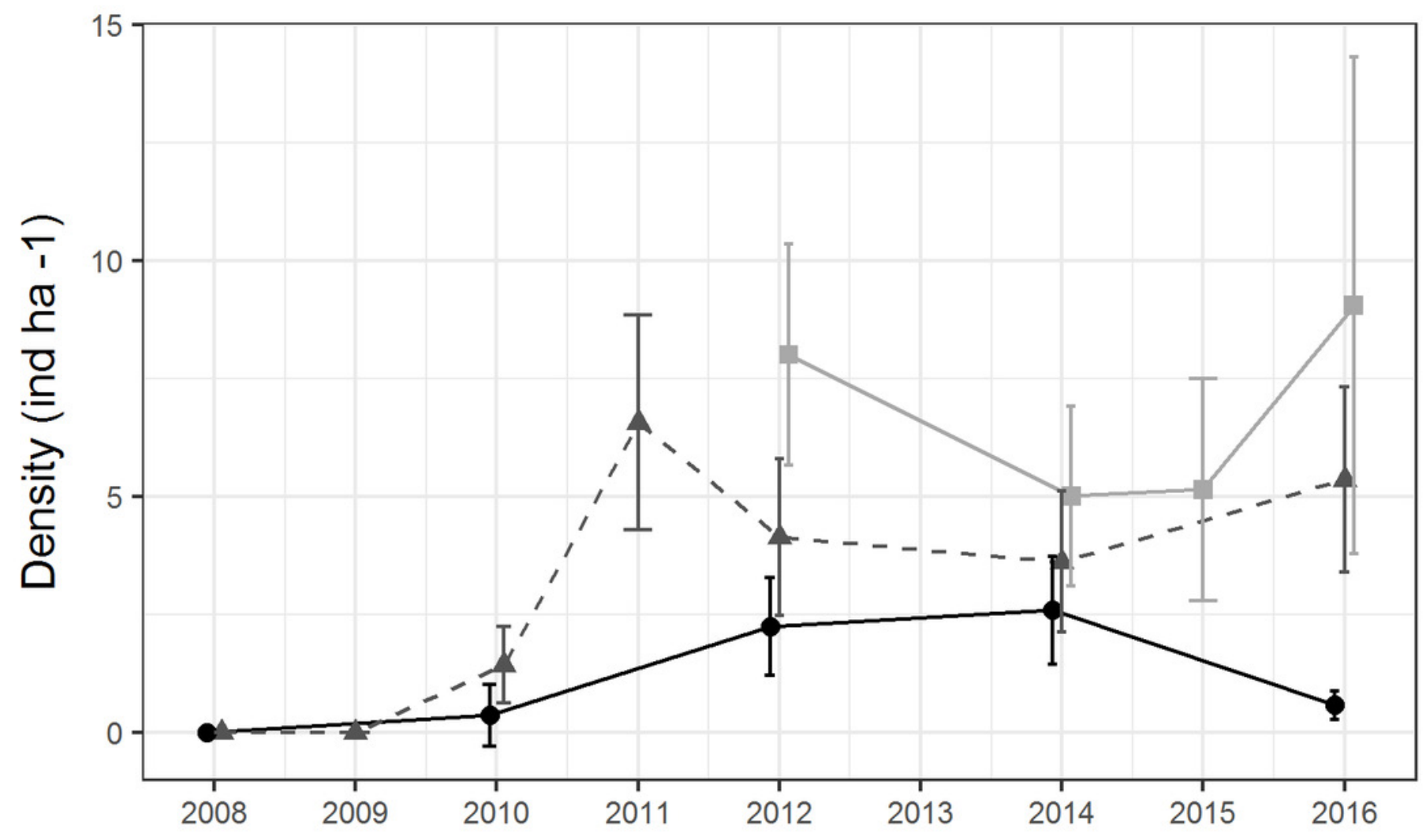




\section{Figure 3}

Lionfish density (ind ha-1) by strata for each region in 2014 and 2016 combined.

Bars represent standard error. Values in parentheses are the percentage of area within each region for that strata. Strata abbreviations for the Dry Tortugas are: ISOL_HR (isolated high relief), CONT_MR (continuous medium relief), CONT_HR (continuous high relief), ISOL_MR (isolated medium relief), CONT_LR continuous low relief), ISOL_LR (isolated low relief), SPGR_LR (spur and groove low relief), SPGR_HR (spur and groove high relief); for the Florida Keys: FDLR (forereef $\geq 18 \mathrm{~m}$ depth), FMLR (forereef 6-18 $\mathrm{m}$ depth), HRRF (high relief spur and groove), OFPR (offshore patch reef), MCPR (mid-channel patch reef), INPR (inshore patch reef), and FSLR (forereef $<6 \mathrm{~m}$ depth); for southeast Florida: RGDP1 (high relief deep ridge in Martin County), RGDPO (low relief deep ridge in Martin County), OFFR0 (low relief outer linear reef), PTSH2 (shallow patch reef), PTDP0 (low relief deep patch reef), PTDP1 (high relief deep patch reef), OFFR1(high relief outer linear reef), DPRC0 (low relief deep ridge complex), DPRC1(high relief deep ridge complex), MIDR1 (high relief middle linear reef), MIDR0 (low relief middle linear reef), INNR1 (high relief inner linear reef), NEARO (low relief shallow ridge), NEAR1 (high relief shallow ridge), and INNR0 (low relief inner linear reef). 


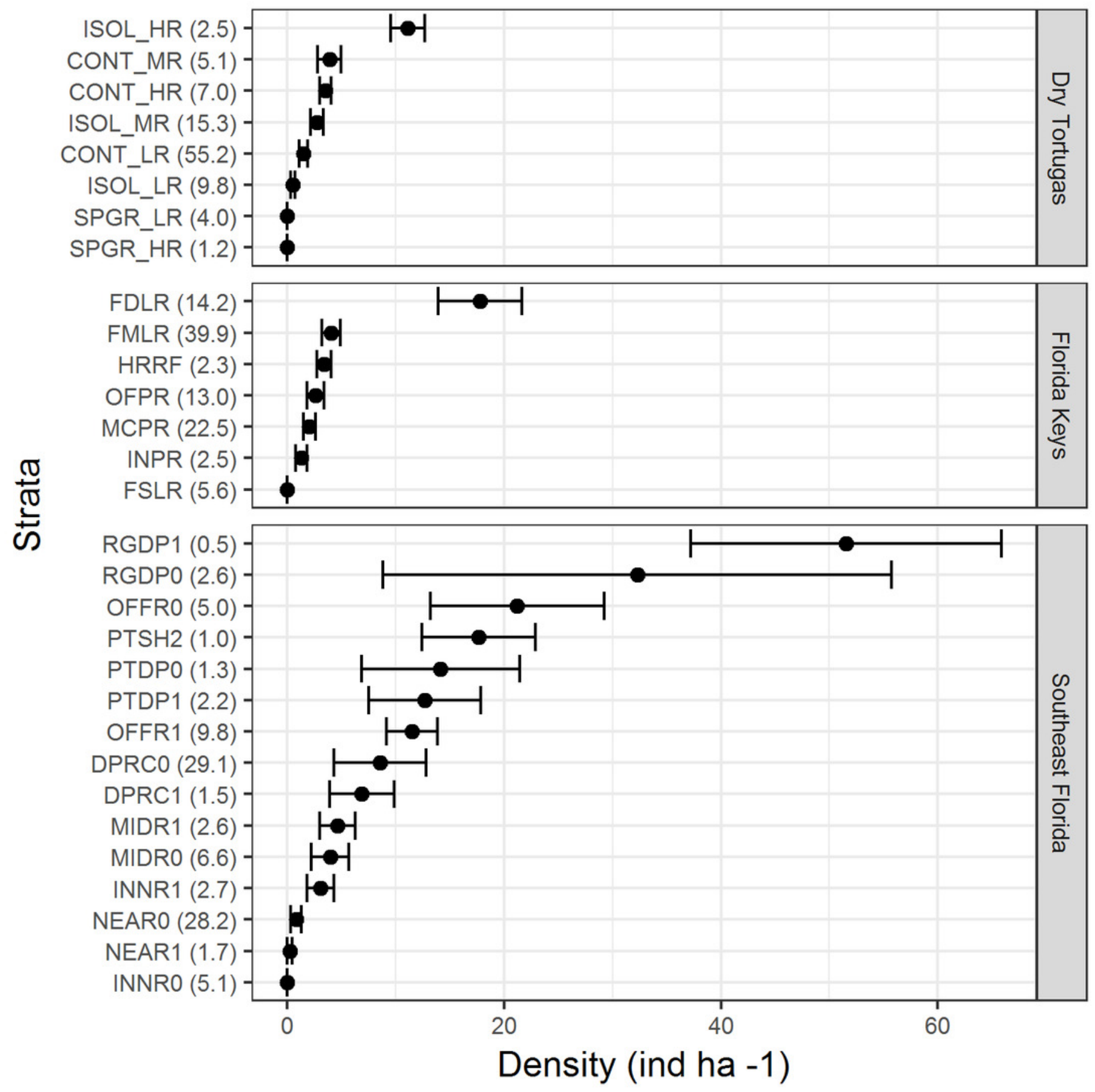




\section{Figure 4}

Density of piscivorous fish with an occupancy rate greater than $1 \%$ in at least one area in 2016.

Lionfish are highlighted by a bold circle and were are ranked $30^{\text {th }}$ out of 66 in the Dry Tortugas, $17^{\text {th }}$ out of 66 in the Florida Keys, and $13^{\text {th }}$ of 68 in southeast Florida. Density (ind $\mathrm{ha}^{-1}$ ) is presented along a logarithmic scale on the $\mathrm{x}$-axis. 


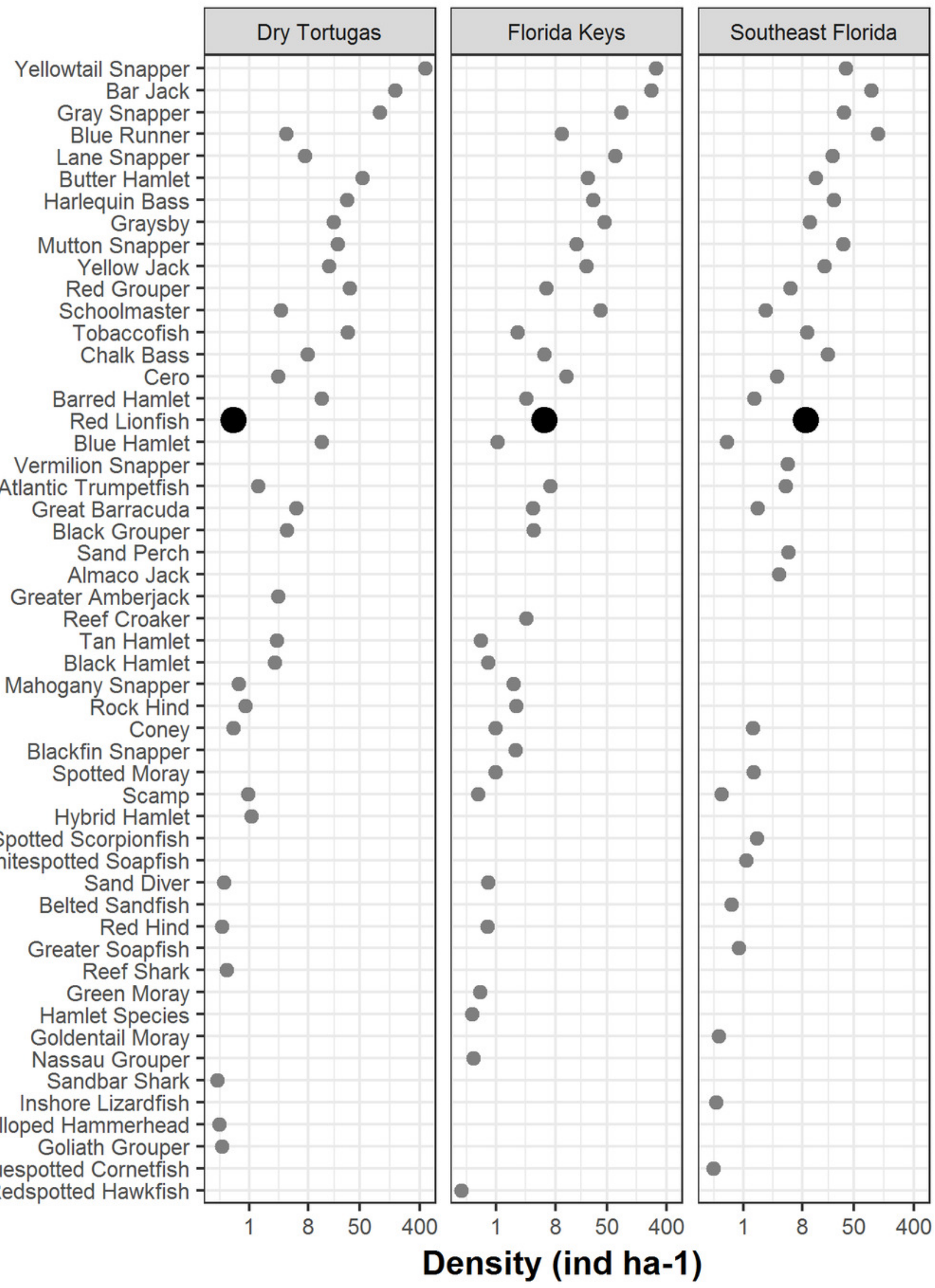


Figure 5

Regional density estimates (ind ha-1) of lionfish and several groups of potential lionfish predators and competitors in 2016.

Bars represent $95 \%$ confidence intervals. Y-axis scales are different for each panel.

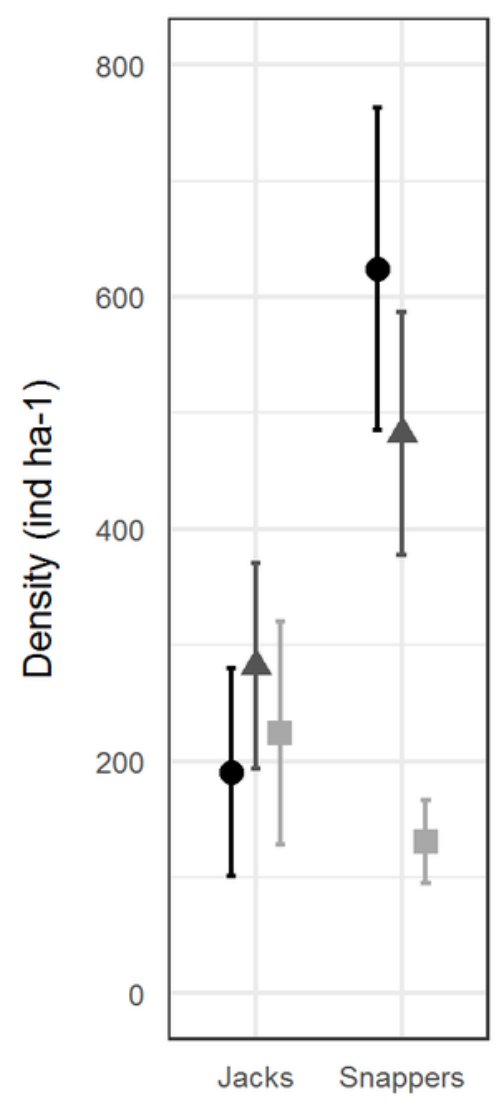

- Dry Tortugas - Florida Keys - Southeast Florida

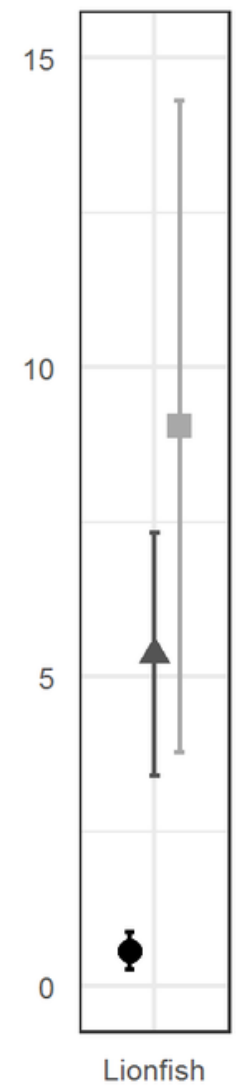




\section{Table $\mathbf{1}$ (on next page)}

Number of secondary sample units (SSUs) surveyed and lionfish counted in each region since 2010. 


\begin{tabular}{c|cc|cc|cc} 
& \multicolumn{2}{|c|}{ Dry Tortugas } & \multicolumn{2}{c|}{ Florida Keys } & \multicolumn{2}{c}{ Southeast Florida } \\
Year & SSUs & Lionfish & SSUs & Lionfish & SSUs & Lionfish \\
\hline \hline 2010 & 703 & 4 & 740 & 37 & & \\
2011 & & & 789 & 181 & & \\
2012 & 813 & 136 & 803 & 91 & 1073 & 390 \\
2013 & & & & & & \\
2014 & 704 & 111 & 860 & 88 & 605 & 156 \\
2015 & & & & & 417 & 112 \\
2016 & 544 & 55 & 797 & 121 & 570 & 181
\end{tabular}

1 